\title{
GCU
}

Glasgow Caledonian

University

University for the Common Good

\section{Innovating the problem away? A critical study of anti-rape technologies}

White, Deborah; McMillan, Lesley

Published in:

Violence against Women

DOI:

$10.1177 / 1077801219856115$

Publication date:

2020

Document Version

Author accepted manuscript

Link to publication in ResearchOnline

Citation for published version (Harvard):

White, D \& McMillan, L 2020, 'Innovating the problem away? A critical study of anti-rape technologies', Violence against Women, vol. 26, no. 10, pp. 1120-1140. https://doi.org/10.1177/1077801219856115

\section{General rights}

Copyright and moral rights for the publications made accessible in the public portal are retained by the authors and/or other copyright owners and it is a condition of accessing publications that users recognise and abide by the legal requirements associated with these rights.

Take down policy

If you believe that this document breaches copyright please view our takedown policy at https://edshare.gcu.ac.uk/id/eprint/5179 for details of how to contact us. 
INNOVATING THE PROBLEM AWAY? A CRITICAL STUDY OF ANTI-RAPE TECHNOLOGIES

\author{
*Dr. Deborah White \\ Associate Professor/Department of Sociology \\ Otonabee College OC 231 \\ 1600 West Bank Drive \\ Trent University \\ Peterborough, Ontario, Canada K9L 0G2 \\ Phone: 7057481011 ext. 7865 \\ Fax: 7057481213 \\ Deborahwhite2@trentu.ca
}

Dr. Lesley McMillan

Professor of Criminology \& Sociology

Glasgow School for Business \& Society

Glasgow Caledonian University

Lesley.McMillan@gcu.ac.uk

Keywords: rape, sexual assault, prevention, technologies 
Innovating the problem away? A critical study of anti-rape technologies

\begin{abstract}
In the context of expanding preventative strategies for addressing sexual violence, we are witnessing the emergence of an array of new anti-rape technologies targeted at women. These tools, promoted primarily through the internet, include a variety of apps for mobile phones, signal and alarm emitting wearable technologies, and internal and external body devices. Based on analyses of websites promoting such instruments, we critically examine these devices with respect to their possible benefits, limitations and unintended physical, social and legal consequences for women. We suggest that unanticipated outcomes may undermine both victims and their cases; those the technologies are ostensibly designed to help.
\end{abstract}


Innovating the problem away? A critical study of anti-rape technologies

\section{INTRODUCTION}

It has been widely documented that sexual assault and rape continue to be significant problems across the globe (Du Mont \& White, 2013; Htun \& Weldon, 2012). In the U.S., it is estimated that 1 in 5 women has experienced sexual violence (www.cdc.gov/violenceprevention). Of those that are reported, case attrition is high and conviction rates are low (see McMillan \& White, 2015). The fact remains that even following decades of policy and law reforms undertaken in many countries (see Corrigan, 2013; McMillan, 2007), criminal justice responses worldwide have not led to the reduction or elimination of sexual assault and rape.

In the face of the persistence of sexual violence and concomitant failure of official channels to diminish its prevalence, there has been a rise in responses to sexual violence centred on particular prevention strategies (see Hall, 2004; Messner, 2016; Powell \& Henry, 2014) emerging largely from outside of the criminal justice system. Self-defence training, for instance, has increasingly been presented as a strategy for protecting women against sexual assault in both the scholarly literatures (see for example, Cahill, 2009; Campbell, 2005; Hollander, 2014, 2018; Senn et al., 2015), and in non-academic contexts, where more and more community, educational and commercial facilities are offering self-defence lessons. Recently there has also been a growing interest in 'bystander prevention' initiatives, particularly in North America, where programs such as "Green Dot", "It's On Us" or the "Know Your Power" social marketing campaign offer training resources aimed at fostering bystander intervention behaviour in individuals as part of an effort to end sexual violence. Such programs are intended to prepare citizens (often high school, college and university students) to recognize potentially dangerous 
Innovating the problem away? A critical study of anti-rape technologies

situations and take prosocial action to intervene (see for example, Coker et al., 2011; Potter \& Stapleton, 2011).

This intensified focus on sexual assault prevention activity has more recently been accompanied by a proliferation of potential technological solutions, aimed primarily at women. These technologies include a variety of apps for mobile phones, signal and alarm emitting wearables, and internal and external body tools. While engaging devices to protect a woman from sexual violence is not new - the chastity belt dates back hundreds of years - these technologies are not only designed to prevent rape and sexual assault, but in some instances, record evidence for possible future court use. Emerging from both public and commercial sectors, this expansion is in part a result of the widespread availability of digital communications, which provides not only a platform for the function of some of these antisexual violence tools, but also a means to announce, promote and market them. While these rape prevention technologies have received a considerable degree of attention in news and popular media outlets in recent years, relatively little scholarly research has been dedicated to their study.

In 2012, Cumiskey and Brewster published results from a survey study of female college students on the ways in which subjects imagined their mobile phones in relation to personal safety. They found that a significant proportion viewed these devices as potentially powerful weapons of protection. In an empirical analysis of apps for mobile phones developed for prevention of sexual violence, Bivens and Hasinoff (2017) concluded that their design tends to be reflective and reinforcing of rape myths, particularly the notion of 'stranger-danger'. Another 2018 study on the use of an anti-abuse app demonstrated low uptake among women participants who employed it over a period of time (Blayney, Jenzer, Read, Livingston, \& Testa). White and 
Innovating the problem away? A critical study of anti-rape technologies

Rees (2014) examined one novel anti-rape technology, known as the Rape-aXe, with respect to its capacity to serve as a viable means of self-defence. In considering the proposed device in relation to the assumptions and claims made about it, they concluded that this barbed condom to be worn internally by women in order to latch on to a penis in the event of unwanted vaginal penetration - was highly problematic and served to reinforce certain myths about the nature of rape, sexual assault and victims (see also, Rees \& White, 2012).

Building upon this small body of work, it was our aim to look beyond a single anti-rape device and consider a fuller range of those designed to prevent or end sexual violence. Through a systematic examination of internet sources, we sought to i) identify and present a comprehensive list of proposed or existing anti-rape technologies; ii) chronicle the corresponding claims made regarding what these tools might accomplish and; iii) critically consider their possibilities, limitations and wider implications.

\section{METHOD}

In this study, the internet was both our object and our tool of analysis (Flick, 2014), as it has become the primary means through which new anti-rape technologies have been advertised, promoted and discussed. Our focus was not on the interactive aspect of the internet, but on text (Hine, 2000). Text on the internet, however, can be non-linear and multi-layered - with links, sound, pop-ups, videos - transcending local, regional or national boundaries (Flick, 2014). And, although it is capable of providing rich animated material for analysis, the internet can also be a challenge when trying to capture and re-present the key information from a website or blog. Nonetheless, we drew on what we felt to be the valid and core content across these sources as systematically as possible. 
Innovating the problem away? A critical study of anti-rape technologies

Between 2015 and the 2018 we used 'google alerts' and 'google scholar alerts', with 12 search key word/phrases, to locate and learn about existing or proposed anti-rape or sexual assault devices in a comprehensive manner. The descriptive content derived from these searches was generated by those involved in the creation and promotion of a given anti-rape device, as well as third party reporting of and/or commentary in relation to it. Our sampling frame was dictated by these alerts, from which we purposefully sampled those items that related directly to technologies of sexual assault prevention. Often, several alerts referred to the same item. The alerts produced anywhere from 2 - 30 entries a day. Eliminating those that were not relevant and those that were repeat postings, we estimate that we drew upon approximately five a week that were either introducing a new technology or discussing one that we had previously charted. We categorized the technologies presented into three types: 1) corporeal devices (to be worn on or in women's bodies); 2) communication devices (most typically connected to mobile phones) and; 3) corporeal/communication devices (those that function as both, for example, an item worn on the body that also serves to communicate to others). Of items identified, not all were available to the public at that time. Thus, to the extent that we could ascertain from internet sources, we further inventoried each device a "prototype" or "currently funded or available". As research was ongoing, and in light of the fact that some products and websites were altered or discontinued, we revisited all sites reported on in this paper within one month of submission for review. Early and provisional findings and analyses were blogged at https:/genderpoliticsatedinburgh.wordpress.com/2017/11/25/technologising-rape-and-sexualassault-can-we-really-innovate-the-problem-away/amp/? 
Following Elo and Kyngas (2007) who stated that the aim of content analysis "is to attain a condensed and broad description of the phenomenon, and [that] the outcome of the analysis is concepts or categories describing the phenomenon" (p. 18), our primary focus in examining this content was determining what technologies were either available (or being proposed), and the nature of the claims being made with regard to these. We do note that although the internet is capable of providing rich illustration of social processes, and is a bountiful source of accessible data, there are limitations to analysing web documentation. Foremost, we cannot fully understand the intentions and understandings behind those who create and promote these antirape technologies through simply reading what they have posted or been quoted as saying on internet sites. In taking the data largely at face value, we are often left to read between the lines and, to a degree, speculate on issues of 'authenticity and contextualization' (Flick, 2014). With that, below we present our typology of anti-rape technologies, providing several examples representative of each category. We examine the discursive claims made regarding what these innovations may accomplish, and present an analysis based on five key analytic themes rooted in feminist scholarly research and critique on sexual violence.

\section{Findings (1): Description of Anti-Rape Technologies}

Drawing upon the data collected, we first examined our findings in terms of how these anti-rape technologies could be descriptively classified. We highlighted three key categories: corporeal devices, communications tools, and those that functioned as both corporeal and communications instruments simultaneously. While it is not possible in this space to describe all of the anti-rape technologies identified, we offer an abbreviated list of those within each of the three category types used for classification. 
Innovating the problem away? A critical study of anti-rape technologies

\section{Corporeal Technologies}

Of those anti-rape technologies that are worn on or in a woman's body, some are designed to primarily harm an attacker, including the Rape-aXe prototype described above, as well as:

- FemDefence (prototype) - a tampon-like item containing a sharp pin intended to pierce a penis in the event of unwanted penetration (Murano, 2013).

- Anti-molestation jacket (prototype) - a vest-like jacket that, at the push of a button, discharges 110 volts of electricity outward to stun a potential perpetrator in the case of unwanted advances (Murano, 2013).

Some bodily devices are intended to directly prevent a potential perpetrator access to a woman:

- AR Wear (commercially available) - a line of anti-rape undergarments, shorts and running pants made of materials that cannot be cut or pulled off, only unlocked (indiegogo.com/projects/ar-wear-confidence-protection-that-can-be-worn). Safe Shorts similarly consist of cut-resistant material and an alarm and safety lock (safeshort.eu).

- The True-love Bra (prototype) - designed to be unhooked only when a woman is experiencing feelings of 'true love', detected through the secretion of certain chemicals (Gray, 2014).

- Protective belt buckle (ongoing online funding effort) - requiring two hands to unlock, intended to deter potential rapists (indiegogo.com/projects/fashion-against-rape--2).

A number of corporeal tools are designed not only to deter, but to repel a would-be attacker:

- Invi Bracelet (commercially available) - marketed as a stylish "non-violent self-defense bracelet that uses smell to repel". When in a threatening circumstance, a woman opens the bracelet and a pungent smell is released to compel a potential assailant to leave 
Innovating the problem away? A critical study of anti-rape technologies

(invi.world). Perltect Bracelet (prototype) similarly discharges a strong odour, one that will cling for several months, in order to link a potential assailant to the woman/crime scene (Buck, 2016).

- Pepper spray stilettos (prototype) - with 5 inch heels that contain a concealed canister of pepper spray within the hollowed out heel for women to access in order to ward off a possible attacker (Agencia EFE, 2017).

Finally, certain corporeal items such as Undercover Colors (soon to be available), a nail polish that changes colour when a woman dips her fingers in her drink if it contains a 'date rape' drug (Undercovercolors.com), are designed to primarily to alert women to possible danger.

Communications Technologies

Of the communications technologies aimed at rape prevention identified, most were some form of 'app' for mobile devices. There are currently over 200 such apps for sexual violence prevention available in the App Store and Google Play (Bivens \& Hasinoff, 2017). Some are solely about alerting others to possible danger. For example:

- Circle of 6 - one of the winning apps in a U.S. government competition as part of a larger 'apps against abuse' campaign, allows women to inform up to six pre-determined people if they have concerns about the possibility of an attack (circleof6app.com).

In some instances, apps include features that allow documentation of any possible incident:

- bSafe - connects its owner with friends/family and also has a "Follow Me" feature, which allows the user's contacts to track her journey in real-time, along with an "I'm Here" feature which indicates when she has arrived at her destination, and an alarm that triggers 
Innovating the problem away? A critical study of anti-rape technologies

when users do not check-in on time. A video recording begins once the alarm is activated and is sent to a 'guardian' (getbsafe.com).

Others apps are focused on the issue of consent, ensuring that any sexual interaction that takes place has been documented as acceptable to the woman and not a sexual violation:

- We-consent - those about to engage in sexual relations utilize this app to state their names and "yes" to a pending sexual encounter. Video of these statements is recorded, timestamped, geo-coded, encrypted and stored offline to be accessed by law enforcement or university officials if required. There is a feature that allows the woman to rescind consent at any point (we-consent.org). The Yes to Sex dating app operates similarly (yestosex.com), as does Legalfling, which creates "legally binding agreement about sexual consent ... verifiable through the blockchain technology" (legalfling.io).

Some apps are intended to facilitate bystander intervention as a means of rape and sexual assault prevention. The Night $\mathrm{Owl}$, designed for college-aged students at parties, allows them to discreetly contact the host or another party-goer to intervene if they feel that a female may be in a troublesome situation. Similarly, the SPOT app is connected to a smart wristband to be worn by a party host through which alerts can be sent by others at a party to indicate having spotted a problem (abcnews.go.com/US/apps-aim-prevent-sexual-assault-rapecampus/story? $\mathrm{id}=25176260)$. Prevention apps would also include those intended as victim alerts to areas deemed as dangerous. For instance, HarassMap, originating in Egypt, is designed as a violence mapping tool to warn women of potentially unsafe areas (such as in parts of Cairo), based on SMS messages received. These are posted in real time on a map (harassmap.org).

Corporeal/Communications Technologies 
Innovating the problem away? A critical study of anti-rape technologies

The third category of anti-rape technologies catalogued are those that combined a wearable technology with the capability to also communicate with others. In some instances, the device is intended to both alert others and deter a would-be assailant, such as the,

- The Smart Jewelry Bracelet (prototype) - which contains advanced sensors that analyse the wearer's regular movements and vital signs in order to detect if they suddenly change. If so, the bracelet discharges a loud sound and flashing red strobe lights. It also connects to a woman's smartphone to send messages and her location to her contacts and emergency professionals (Womack, 2018).

Some are centred primarily on alerting others. For example:

- Pro(Tech)t iuvo bracelet (in development) - is part Fitbit, part panic button. The cellphone independent device uses GPS technology to alert campus police to a possible attack through a secure website (Trumbell).

Other technologies (some available, some in development) that operate similarly include the Athena Safety Wearable (roarforgood.com), Secure Couture's Stiletto line of jeweled charms for necklaces and bracelets (Sciarretto, 2015), and the Revolar Instinct, marketed as a "fashionable device" with a step-counter and the capability to send out help signals. It also has a "Ring Me" feature, which lets users click a button to call their own phone and excuse themselves from "bad dates" (Revolar.com). Some of those that are designed to both alert others and deter also feature potential recording for documentation for possible future use:

- The Personal Guardian (pending commercial availability) - a wearable communication device that attaches to a bra strap or other area of clothing and has two buttons that when pushed activate a woman's mobile phone, which then sends notification to a monitoring station. That signal is to be interpreted by staff receiving it as an indicator of any notable 
change in the owner's breathing, or other bodily indicators of panic. If there is concern, police (as well as select friends/family) are alerted through GPS technology in the phone as to her whereabouts. The phone can also function as a recording device to potentially provide evidence for later use in court (theguardian.com/business/2015/aug/02/theinnovators-personal-rape-alarm-fast-track-police).

- Intrepid (prototype) - an electronic bra sticker that, by monitoring the wearer's regular movements, can detect changes that may indicate forcible grabbing or touching, triggering a text message to her phone to inquire as to whether she is in distress. If she replies yes, or if there is no reply, a text is sent to a network of friends and family. It too can record encounters for use later in court (circa.com).

Findings (2): Discursive Claims Made for Anti-Rape Technologies

Beyond identifying technologies designed for the prevention of sexual violence, we were interested in the presumptions surrounding them. We examined the claims made on product websites and related posted interviews/statements by developers, promoters and commentators regarding what they appeared to believe these devices could achieve in relation to sexual assault and rape prevention. While some assertions were very pragmatic, of limited scope, and clearly indicated that the tool in question was perhaps just one solution to a much more complex problem, overwhelmingly, the language characterizing these products concerned their ability to protect and empower women, and, for some, end sexual violence, or at least reduce or prevent it:

The company was founded to prevent sexual assault ... and Revolar's technology is used by people all over the world to stay safe (prweb.com). 
Innovating the problem away? A critical study of anti-rape technologies

We have the ambition to make the Invi Bracelet accessible for people all over the world and spread knowledge and awareness on the topic, uniting people globally in the prevention of sexual violence (Invi.world).

[They] . . are working on an app called Ulzi that they hope will eventually put an end to sexual assaults all together (Leslie, 2018).

In some instances, the claim was made that lives will be saved:

Why this one app could save your life (watchovermeapp.com).

A very experienced team of researchers, designers and athletes has developed

SAFE SHORTS to give you the possibility to protect yourself against any unexpected attacks by others (safeshorts.eu).

In others, not only would the technology address the problem of sexual assault and rape, but more broadly change lives and change society:

As a company, we have this one metric that we use to measure success: the number of lives we touch. Thus, we will continue developing solutions to reduce assaults and ideally begin to transform society (theodysseyonline.com/interviewroar-for-good-co-founder-anthony-gold).

They asked me for a design that would help solve a social problem (Agencia EFE, 2017).

It is the newest fashion accessory that may really, truly have the power to change lives (Undercovercolors.com).

The claim was also made that a particular technology could serve to empower women: 
Innovating the problem away? A critical study of anti-rape technologies

ROAR for good is taking their mission, to empower women, reduce assaults, and thereby transform society . . (Maher, 2015).

Our goal is to invent technologies that empower women to protect themselves from this heinous and quietly pervasive crime. . . Power must be handed back to women in what is a devastatingly powerless situation (Undercovercolors.com).

Claims or hopes for their technologies were sometimes expressed by developers in terms of how they might assist with the criminal justice processing of sexual assault and rape:

Intrepid has various features but the most important feature that could change the lives of millions of victims is the ability of the device to document the crime. It creates evidence by recording the audio in the background and time. A lot of culprits who get away with crimes due to lack of evidence will be punished with the help of this innovation (Palisetty, 2018).

I want to help jail an attacker (Jackson-Edwards, 2015).

What was also notable in examining the internet discourse on these technologies was the pervasive theme throughout suggesting that the world is unsafe for women:

Every day, women face the threat of harassment, assault, and violence (roarforgood.com).

The co-founder of the "Watch Over Me" app stated on their website: 
Innovating the problem away? A critical study of anti-rape technologies

Crime affects women in every city. Women can be sexually and violently assaulted whether or not they live and travel in emerging markets like India, or mature ones like the US (watchovermeapp.com).

A testimonial on that same website also read:

Just saved my life!" Someone tried to take my phone and car keys and I told him my phone is on watch over me mode and would track him and video him. He looked at me like I was crazy then I shook it and got a video of him and told him the police had it now and he ran away :) Thank u guys! A country girl in a dangerous city! (watchovermeapp.com).

On the "Safe Shorts" website, another testimonial read:

Recently, I haven 't felt safe during my exercises in the forest or on my local running track. More often I have been thinking about a running tight, being able to protect me against sexual assault and rape. It is too simple for other people to strip off my present running tight from my body (safeshorts.eu).

The creator of the two handed belt buckle stated on the "Fashion Against Rape" fundraising site: [y] ou read about rape in the newspapers almost every day. You become anxious and wonder why no one does anything about it (indiegogo.com/projects/fashionagainst-rape--2\#/).

There is a clearly defined assumption behind these technologies: wearing and carrying protective clothing or accessories, or having constant reliance on a mobile device for potential alarm-setting and tracking, is normal and warranted. As the developer of one rape prevention app 
Innovating the problem away? A critical study of anti-rape technologies

stated: "I'd like to think that it would be part of your morning routine - before you go out, you put it on and it just stays with you every day" (theguardian.com/business/2015/aug/02/theinnovators-personal-rape-alarm-fast-track-police).

\section{ANALYSIS \& DISCUSSION}

We began by categorizing a sample of proposed and existing anti-rape technologies, along with claims made regarding their intended purposes and potential capabilities. Drawing on a wide body of scholarly sexual violence research, we considered these anti-rape technologies and the corresponding assumptions about what they might achieve in terms of the following analytic themes: 1) device failure/misuse and unintended physical consequences; 2) normalization and marketing; 3) misrepresentations of sexual assault and rape; 4) misplaced responsibilization: 5) evidentiary ambiguities, unanticipated uses and antithetical outcomes.

\section{$\underline{\text { Device Failure/Misuse \& Unintended Physical Consequences }}$}

Our first point concerns certain logistical issues related to the possibilities of an anti-rape device failing to operate as intended. Along with mechanical or technical malfunctions, which can occur with any kind of technology (including mobile phones losing their charge), there are other factors that could lead to both corporeal and communications devices failing women in those moments they may be depending upon them. For instance, during an assault a woman may not be able to access an alarm button that requires pushing. Similarly, she may not be able to engage an app if she is not holding or near her mobile phone to alert a third party, or to change a consent response to 'no' in the course of a sexual encounter. There may be times, in fact, when third party members are not available to assist. Further, as has been demonstrated, people frequently freeze in dangerous situations. Such "tonic immobility" can leave women paralyzed and unable 
Innovating the problem away? A critical study of anti-rape technologies

to scream or fight back (see for example, Möller, Söndergaard \& Helströmm, 2017), or, in the case of some of these gadgets - unable to engage them in the ways suggested for protection.

Beyond those conditions which might render a device ineffective, there is the possibility that a woman could suffer unintended physical consequences attempting to utilize it in a menacing circumstance. With respect to certain of the corporeal technologies, there is the risk that the woman herself could be damaged: sharp tools intended for internal wear, along with electric voltage clothing, could conceivably malfunction and injure her. Items such as anti-rape pants or complicated belts could be problematic were she to, for instance, require medical attention. Moreover, it could be speculated that should a perpetrator become aware of a woman's attempt to reach for a phone to alert others or trigger an alarm or, if he himself is injured by a device she is wearing or carrying, his angered violence could escalate against her.

Further consequences could result from the potential for increased surveillance of women, particularly in relation to the GPS communication technologies that allow many people to virtually identify where a woman is at all times (e.g., the "follow me" and "I'm here" features of apps such as $b S a f e$ ). While this raises serious privacy concerns and feeds into the historic technological monitoring and policing of women's bodies and movements (see Dubrofsky \& Magnet, 2015), there is also a strong and not necessarily accurate assumption in the anti-rape technology discourse that anyone a woman may contact through an app would have only her safety and best interests at heart. It is possible, however, that a male who follows her electronically could also have ill intent, and that such prevention apps could lead to a form of cyberstalking by those interested in following a woman through her travels and daily routines (see Lemieux \& Felson, 2012; Henry \& Powell, 2016). The current array of existing 'girlfriend tracker' apps underscore this possibility. "Surveillance practices are intimately connected to 
Innovating the problem away? A critical study of anti-rape technologies

stalking and have had tremendous consequences for violence against women” (Mason \& Magnet, 2012, p. 107). In fact, research has shown that mobile devices in general, including those intended for safety purposes, may make users more vulnerable to attack (see for example, Fraser, Olsen, Lee, Southworth \& Tucker, 2010; Southworth \& Tucker, 2006).

\section{Normalization \& Marketing}

The expanded availability and apparent semi-embrace of many of the anti-rape technologies is characterized by the associated role they play in the fear-mongering and further normalizing of sexual assault. As suggested above, much of the discourse behind these devices is based on creating a state of fear, one great enough to impel a woman to adopt tools deemed to be for her protection. At the same time that their promotion is centred on a particularly gendered culture of 'quiet fears of everyday life' (Furedi, 2007; see also, Bedera \& Nordmeyeter, 2015), this sensibility is consistent with a broader culture that normalizes sexual violence and implies its inevitability (Spencer, Mallory, Towes, Stith \& Wood, 2017; see also, Campbell, 2005; Hall, 2004; Hlavka, 2014).

Campbell (2005) has suggested that the normative body of a self-disciplined feminine subject is reproduced through the regularized acts of rape prevention that keep "women locked into specific restricting regimes of the self. ... As directives aimed at women through crime prevention compel the feminine body to dress in certain ways, to avoid certain locales, and so on, .. the female subject, through repeated stylised safekeeping acts, constitutes a particular

femininity; one marked by vulnerability" (p. 120; see also, Hall, 2004). So, in addition to informing how they should dress and accessorize and what they should carry, rape prevention technologies, such as those that indicate potentially dangerous areas for instance, also compel women to police their own movements and shape how they engage with public spaces in 
Innovating the problem away? A critical study of anti-rape technologies

regularized ways. Beyond the realities that many women do not have the luxury of avoiding certain neighbourhoods (they may live or work in them), these technologies serve to impose greater social control over women's daily lives. In this regard, Campbell argues that rape prevention approaches, wherein women are seen and come to see themselves as always vulnerable, in fact increase rather than lessen the possibility of sexual violence as rape comes to appear as inevitable (see also, Bivens \& Hasinoff, 2017; Brooks, 2011).

Further, some developers and organizations behind these anti-rape technologies are declared as non-profit, and, reading their testimonials and interview statements, it appears that many or most are motivated by the best of intentions to serve women and address sexual violence. The Scottish university student who developed the Personal Guardian app stated that she was moved to create a device to make women safer following the rape of her neighbour one night at the end of her driveway (Jackson-Edwards, 2015). In addition to those intending to remain non-profit, in certain instances, social impact entrepreneurs have pledged to contribute a portion of proceeds from the sale of their devices towards initiatives such as anti-violence education programs (e.g., Undercover Nails, roarforgood). At the same time, however, this naturalizing of constant threat and need for vigilance is largely tied to the market. Most of the anti-rape technologies we examined are primarily commercial products. Apps such as Watch Over Me and OnWatch are available for monthly or yearly subscription fees. The Athena Pendant is listed at $\$ 129$ (roarforgood.com), and the Revolar Instinct pre-orders at \$99 (revolar.com). A scan of the Amazon.com website will produce a number of anti-rape devices (primarily alarms) across a range of prices. Even if these products were shown to be effective in eliminating sexual violence, tying rape prevention to the market is problematic on a number of 
Innovating the problem away? A critical study of anti-rape technologies

levels, not the least of which is the reality that not all women and girls can afford such jewellery, clothing, apps, or even mobile phones.

The technologizing of rape prevention, in large part, represents the commodification of women's safety (see for example Hall, 2004). In fact, the hyper-normalization of the threat of sexual violence is highly intertwined with gendered lifestyle consumerism. According to the cofounder of the Athena Pendant: "[i]t is a stylish module that can be worn as a necklace, clipped to a bag, attached to a key fob, or any other location that suits the wearer's lifestyle ... the ultimate accessory for the everyday woman" (theodysseyonline.com/roar-good). The website announcing their product declared, "Revolar Instinct is a fashionable wearable device and stepcounter, designed to stop assaults before they happen ..." (prweb.com). Discussing this routinization of consumption, one commentator observed: "[i]n the promotional video for AR Wear, a woman strikes a pose to check out her anti-rape underwear before sliding on her little black dress and doing her hair, all in one seamless process. Split ends. Deodorant streaks. Sexual assault. How terribly inconvenient” (Robertson, 2014). The role of regularized consumption in the growth of current prevention efforts cannot be underestimated.

\section{Misrepresentations of Rape and Sexual Assault}

Wajcman (1991) has established that technologies are socially shaped. People design and create them, hence the beliefs and biases they hold can become integrated into the devices they produce, and may be articulated through their use (see also, Balsamo, 2011). We would argue that many of the anti-rape technologies proposed or available embody and reproduce certain representations of sexual assault which reflect a number of dominant rape myths that circulate culturally (see Bivens \& Hasinoff; Parnis \& Du Mont, 2006). This becomes problematic in terms 
Innovating the problem away? A critical study of anti-rape technologies

of their potential efficacy at the individual level, and with respect to the reification of erroneous notions of sexual violence more broadly. For instance, many of the corporeal devices and their corresponding discourse (e.g., anti-rape underpants, complex locking system buckles) reinforce the notion of sexual assault as vaginal penetration, suggesting that as long as an attacker cannot remove her bottoms, a woman will be safe. In reality, sexual violence occurs in many different forms and is recognized as such in law throughout much of the world. Beyond penetration of the vagina, sexual assault can include oral rape, penetration of other orifices, and unwanted touching using not only penises, but objects and other parts of the body (Du Mont \& White, 2007).

As Bivens and Hasinoff (2017) noted in their study of rape prevention apps, many of these tools (such as those with built in alarm and communications systems) also feed into the common assumption of 'stranger danger' and the myth that rapists are primarily those unknowns who will attack unsuspecting women (Campbell, 2005). Given this, the logical extension of the belief in technologizing the prevention of sexual assault would be that a woman would need to carry or wear these devices at all times, as a potential perpetrator could be perpetually in her vicinity. Research has clearly shown, however, that this form of sexual assault is not common, as the overwhelming majority of violations are committed by someone known to the victim (Du Mont \& White, 2007; McMillan, 2013), and typically in familiar locations (www.rainn.org). They are lived out through a wide range of coercive and threatening activities. As such, the experiences of actual sexual assaults are largely unanticipated in the design aspects of these technologies. Their predominant features "do not address the forms of coercion that known perpetrators typically use, including emotional manipulation, abusing a power relationship, or targeting intoxicated victims" (Bivens \& Hassinoff, 2017, p. 11). 
Innovating the problem away? A critical study of anti-rape technologies

We observed in this study that, in addition to an over-emphasis on campus sexual assault in relation to that in the general population (when in fact rates among the two groups are broadly similar (Mulla, 2018)), there was a heavy focus on drug-facilitated rape in the prevention discourse. This was the rationale for the production of several products such as bystander alarms, and especially fingernail varnishes and other implements (such as colour changing straws) designed for detection of drugs such as Rohypnol and Gamma Hydroxy Butyrate (GHB). Commonly referred to as 'date rape drugs', these substances are presented as a significant part of the problem of sexual violence. A large American research study, however, indicates that only a small proportion of reported sexual assaults involve the concealed use of such drugs, noting that while incapacitated rape is a problem among women (in college and in the wider population), "the most common rape-risk situation for both adult women and college women is not being rendered intoxicated; it is being taken advantage of by a sexual predator after she has become intoxicated voluntarily [through alcohol consumption]” (Kilpatrick, Resnick, Ruggiero, Conoscenti \& McCauley, 2007, p.5; see also, Horvath \& Brown, 2007). There is, then, an overrepresentation of externally administered drug-facilitated sexual assault in the anti-rape technology discourse.

\section{(Misplaced) Responsibilization}

A commonality across the technologies we examined is that almost all put responsibility for rape/sexual assault prevention on everyone except perpetrators and potential perpetrators. In addition to a growing emphasis on the role and possible technologization of bystanders, foremost, they are focused on women taking routine measures for their own safety. Talk is of risky places, activities and substances, rather than risky men and their behaviours (see also, Bedera \& Nordmeyer, 2015; Berrington \& Jones, 2002). Dovetailing with the neoliberal shift 
Innovating the problem away? A critical study of anti-rape technologies

from state to individual 'self-help' responsibility for crime prevention (O’Malley, 1996), the historic cultural expectations placed on women for their own safety from male aggression have become intensified (see Hall, 2004), creating fertile ground for the embrace of individualized technological solutions. While such responsibilization is not new (Brooks, 2011; Stanko, 1997) women have always been expected to routinely watch out for how much they drink, what they wear, where they go - it becomes enhanced with the possibility of having to wear and carry new devices to prevent being sexually assaulted. And, with a greater arsenal of tools to ward off would-be assailants, there is even less excuse for 'responsible women' not to be accountable for reading potentially dangerous situations and taking what action possible to thwart those (see Walklate, 1997). Women who are tasked with engaging in prescribed conduct may find themselves subjected to victim-blaming if they are not successful. "The conflicting expectations that women are vulnerable and that women should prevent their own sexual assaults leads to blaming rape victims for not doing enough" (Bedera \& Nordmeyer, 2015, p. 541; see also, Bivens \& Hassinoff, 2017; Ferrão \& Gonçalves 2015).

There is potential for another form of responsibilization of women who have been sexually assaulted should they become engaged with the criminal justice system, where the tendency towards expecting victims to have exhibited 'common sense' norms of prevention behaviour may play out in particular ways. With a growing number of technologies available for the presumed enhancement of their safety, these women could be subjected to new forms of doubt and suspicion. Compounding a long tradition of interrogation regarding a victim's character, past, lifestyle, clothing choices, and activities, women could also be expected to respond to questions of why they had not utilized precautionary devices: Why had she chosen not to inform family and friends of her whereabouts or alert them when she felt threatened; why 
Innovating the problem away? A critical study of anti-rape technologies

had she not resisted an assault with some anti-rape gadget; why had she not taken advantage of a drug-detecting cosmetic? Criminal investigations and prosecutions have notoriously revolved around doubt of a victim (McMillan \& White, 2015; White \& McMillan, 2018), as well as questions regarding her efforts to resist or prevent an assault. While not formally required by law in most jurisdictions, "[r]esistance remains at the center of investigative and legal decisionmaking, defense attorney questioning, and jury expectations" (White \& Rees, 2014, p. 363; see also, Ellison \& Munro, 2009, Lievore, 2005, Rees, 2010). With more and more products aimed at women for the stated purposes of resisting an assault, those who choose not to engage with safety devices could find their credibility undermined.

Moreover, unlike many crimes, rape and sexual assault typically do not have witnesses (see White \& Du Mont, 2009), making successful prosecution uniquely challenging. As such, a greater burden often falls on these victims to participate in criminal justice processes and provide evidence of their own assault. And, research suggests that unwillingness to engage in victim interviews, forensic medical examinations (having a rape kit done) or investigative and prosecutorial processes is often seen as an indicator of a false report (Corrigan, 2013; McMillan, 2018; Parnis \& Du Mont, 2006). In light of this, and of those anti-rape technologies that promise not only prevention or mitigation, but the documentation/collection of evidence of an assault for legal purposes, it is not unreasonable to assume that if documentation devices became a regularized feature of the anti-rape technologies arsenal, victims may find themselves questioned as to why they chose not to be vigilant in securing proof to help their own future cases.

\section{Evidentiary Ambiguities, Unanticipated Uses \& Antithetical Outcomes}


Innovating the problem away? A critical study of anti-rape technologies

For many of the technologies that have attached to them the claim of 'evidence gathering' capacity, there is an ambiguity about the nature of that evidence and what it is likely to produce proof of. For instance, what would video/audio recordings actually document other than the possibility that the accused was present during an alleged incident? It is not necessarily the case that a woman will scream out or clearly articulate that she is being raped, given that sexual assaults may be conducted through force and implicit threat. A bracelet that releases a pungent odour intended to cling to a presumed assailant for future identification could similarly produce ambiguous evidence. Since each bracelet does not possess its own distinctive smell, it would be difficult to prove that someone marked with the scent was actually in sinister contact with the complainant. All that could be established would be that the accused was in proximity to someone who had a bracelet. And, since identification of an assailant is not generally the issue at the centre of a sexual assault, even if the accused was the only person near the sexually assaulted woman, the defence could fall back on the traditional legal claim that the sexual encounter that was consensual (see Du Mont \& White, 2007).

There is also the possibility of anti-rape technologies producing evidence which could actually be used against the victim who collected it. As outlined above, a number of mobile apps have been designed to audio and video record interactions and violable activities. While it is difficult at this time to anticipate exactly how such technologies might be adopted in the processing of sexual assault cases, or who might have access to them and for what purposes, we can speculate on possible outcomes. Writing on the 'digital traces' that may constitute novel evidence of sexual violence within the criminal justice system, Dodge (2017) examined the ways such evidence may either increase the likelihood of positive legal outcomes for women, or be used by the defence as a means of arguing that a victim did not act 'appropriately', and thus 
Innovating the problem away? A critical study of anti-rape technologies

work against her case. For example, with apps that both track a woman's whereabouts and record her agreed-upon sexual encounters there is the potential that data produced by women themselves could be used as evidence suggestive of behaviours such as promiscuity or a lack of responsibility (e.g., frequenting drinking establishments alone). As Dodge noted,

[w] hile feminists have long recognized the dangerous role of the 'ideal victim' expectation within the criminal justice system, this becomes additionally complex in the digital age, as digital evidence . . . can be misconstrued and can become an effective tool for invalidating victims' complaints or arguing that their pre- or post-assault behavior was not indicative of a 'true victim' (2017, p.15).

Moreover, as research has shown that consistency in a victim's narrative across the criminal justice process is often key to her credibility (Gotell, 2002; McMillan, 2018; McMillan \& Thomas, 2009; McMillan \& White, 2015;), there runs a risk that there may be some variation across what a technology records, and what a woman recounts to various professionals (medical, police, lawyers) regarding the details of an assault, especially given the well-documented fragmentation of memory that can accompany traumatic events such as rape (Halligan, Michael, Clark \& Ehlers, 2003). Should there be inconsistencies between the evidence a woman records and her own narrative, which would be privileged in case processing and in court?

Finally, many of the anti-rape technologies examined are based on a woman being able to instantaneously identify and assess a possible threat of danger and act immediately by turning on some device. Not every male walking behind a woman in an isolated portion of a parking garage or down a street at night, however, has the intention of raping her. And yet, what the promotion of these technologies suggests is that this is a frequent occurrence, and one that requires her 
continuous judgment as to someone's intent. It is conceivable that some men could be erroneously caught in a situation involving alarms, recordings, and other impacts (e.g., pepper spray, a clinging stench). Similarly, sensors in wearable tools could be triggered in non-assault situations, and were gadgets like a Rape-aXe to be worn regularly, there is the chance that an unplanned consensual sexual encounter could accidentally lead to serious penile damage. Beyond the risk of over-activating devices such that those who are alerted and expected to respond become fatigued by or suspicious of recurrent notifications of potential danger - it is difficult to imagine police responding to a wide population of women continually sending help alerts that may or may not reflect a truly threatening situation - these technologies could lead to a plethora of new legal complications such as men's possible claims of entrapment (see White \& Rees, 2014) or eventual wrongful convictions (see Leonetti, 2017). Clearly, the ambiguities, the long-established anti-woman biases, and the possibilities of antithetical outcomes make the evidentiary promises of anti-rape technologies questionable.

\section{CONCLUDING THOUGHTS}

It was our aim in this study to chronicle the growing array of anti-rape technologies and the discursive claims accompanying them, and to critically assess their potential capabilities, limitations and implications. We presented a sample of corporeal, communications, and corporeal/communications technologies and the presumptions associated with them regarding the dangerous world women live in and the promise of these tools to empower them, keep them safe, and in some instances, end sexual violence altogether. Our analysis of these devices was based on five themes: device failure/misuse and unintended physical consequences; normalization and marketing; misrepresentation of sexual assault and rape; misplaced responsibilization; and, evidentiary ambiguities, unanticipated uses and antithetical outcomes. Reflecting upon these 
Innovating the problem away? A critical study of anti-rape technologies

thematic analyses, it is our conclusion that the widespread adoption of such technologies could compound existing problems with sexual assault, as well as give rise to new ones, potentially undermining both victims and their cases; those the tools are ostensibly designed to help.

Further research on the potentially wide-ranging implications of anti-rape technologies is certainly warranted. While we have presented our own analyses rooted in the extant empirical research on a) the prevalence and nature of rape/sexual assault and, b) the cultural context of rape/sexual assault, particularly the pervasiveness and impact of 'rape myths' regarding sexual assault, victims and criminal justice, we have little sense of how these technologies might be received and utilized. Qualitative studies focused on those at whom the technologies are targeted could address important questions such as: What are different women's perceptions of these technologies in relation to their understandings of sexual assault? To what extent would they welcome or reject such devices and why? How do those who may have purchased rape prevention tools engage with them? And, do these instruments ultimately serve to alleviate or exacerbate fears of sexual violence. We have recently been awarded funding to explore these areas further.

It was not our objective to malign those working to prevent sexual violence, many who have been, no doubt, motivated by a strong desire to see it end. We do believe, however, that despite good intentions, and the possibility that in certain circumstances a device could in fact foil a particular sexual assault or provide evidence that could advance a case in the criminal justice system, these anti-rape and prevention technologies do not, and cannot, meet the grand discursive claims of their proponents. Echoing Bivens' and Hasinoff's conclusions about the inefficacies of current rape apps, we agree that "the notion that this is a meaningful way to end 
rape implies that rape, as a broad social problem, actually cannot be prevented, and can only be avoided by vigilant and responsible individuals" (2017, p. 15). Offering up an assortment of tools to wear and use may make individual women and those concerned for them feel that they are safer, but, is this ultimately a false sense of security?

We would suggest that as these technological responses are situated within, and highly compatible with, neo-liberal culture and capitalism, they serve to further privatize and atomize the problem of sexual violence. And, just as individualized efforts made to increase self-defence training for women have not eradicated rape and sexual assault, selling women bodily and communications technologies to incorporate in their daily lives is also not likely to end this insidious historic problem of global proportion. Beyond the many actual and potential problems of these anti-rape devices that we have discussed, perhaps the key limit to all such technologies is that they fail to address the root structural causes of rape and sexual assault, and to address those truly responsible for it. It is our contention that profound collective social and cultural change aimed at unseating the patriarchal and rape-supportive culture within which sexual violence occurs with such impunity is required. 
Innovating the problem away? A critical study of anti-rape technologies

\section{REFERENCES}

Agencia EFE (November 13, 2017). High heels with pepper spray, new self-defense weapon for Mexican women. Retrieved from https://www.efe.com/efe/english/life/high-heels-withpepper-spray-new-self-defense-weapon-for-mexican-women/50000263-3436228.

Ariana, B. (2013). The usual suspects: A feminist critical discourse analysis of media representations of responsibility for sexual assault prevention (Doctoral dissertation, University of British Columbia).

Balsamo, A. (2011). Designing culture: The technological imagination at work. Durham NC: Duke University Press.

Baer, H. (2016). Redoing feminism: Digital activism, body politics, and neoliberalism. Feminist Media Studies, 16(1), 17-34. Bedera, N., \& Nordmeyer, K. (2015). Never go out alone: An analysis of college rape prevention tips. Sexuality \& Culture, 19(3), 533-542.

Berrington, E., \& Jones, H. (2002). Reality vs. myth: Constructions of women's insecurity. Feminist Media Studies, 2(3), 307-323.

Bivens, R., \& Hasinoff, A. (2018). Rape: is there an app for that? An empirical analysis of the features of anti-rape apps. Information, Communication \& Society, 21(8), 1050-1067.

Blayney, J., Jenzer, T., Read, J., Livingston, J., \& Testa, M. (2018). Enlisting friends to reduce sexual victimization risk: There's an app for that... but nobody uses it: Enlisting friends to reduce sv risk. Journal of American College Health, 1-22, doi/full/10.1080/07448481.2018.1446439 . 
Innovating the problem away? A critical study of anti-rape technologies

Brooks, O. (2011). 'Guys! Stop doing it!': young women's adoption and rejection of safety advice when socializing in bars, pubs and clubs. The British Journal of Criminology, 51(4), 635-651.

Buck, S. (June 20, 2016). Why is pepper spray still the 'best' rape prevention tech? Retrieved from https://timeline.com/why-is-pepper-spray-still-the-best-rape-prevention-tech6959ce9731dc.

Cahill, A. (2009). In defense of self-defense. Philosophical Papers, 38(3), 363-380.

Campbell, A. (2005). Keeping the 'lady'safe: The regulation of femininity through crime prevention literature. Critical Criminology, 13(2), 119-140.

Coker, A., Cook-Craig, P., Williams, C., Fisher, B., Clear, E., Garcia, L., \& Hegge, L. (2011). Evaluation of Green Dot: An active bystander intervention to reduce sexual violence on college campuses. Violence Against Women, 17(6), 777-796.

Corrigan, R. (2013). The new trial by ordeal: rape kits, police practices, and the unintended effects of policy innovation. Law \& Social Inquiry, 38(4), 920-949.

Cumiskey, K., \& Brewster, K. (2012). Mobile phones or pepper spray? Imagined mobile intimacy as a weapon of self-defense for women. Feminist Media Studies, 12(4), 590599.

Dodge, A. (2017). The digital witness: The role of digital evidence in criminal justice responses to sexual violence. Feminist Theory, 1464700117743049.

Dubrofsky, R., \& Magnet, S. (Eds.). (2015). Feminist surveillance studies. Durham, NC: Duke University Press. 
Innovating the problem away? A critical study of anti-rape technologies

Du Mont, J. \& White, D. (2013). Barriers to the effective use of medico-legal findings in sexual assault cases worldwide. Qualitative Health Research. 23(9), 1228-1239.

Du Mont, J., White, D., (2007). The uses and impacts of medico-legal evidence in sexual assault cases: A global review. World Health Organization/SVRI.

Ellison, L., \& Munro, V. (2009). Turning mirrors into windows? Assessing the impact of (mock) juror education in rape trials. The British Journal of Criminology, 49(3), 363-383.

Elo, S., \& Kyngäs, H. (2008). The qualitative content analysis process. Journal of Advanced Nursing, 62(1), 107-115.

Ferrão, M. C., \& Gonçalves, G. (2015). Rape crimes reviewed: The role of observer variables in female victim blaming. Psychological Thought, 8(1), 47-67.

Flick, U. (2014). An introduction to qualitative research. London: Sage Publications Ltd.

Fraser, C., Olsen, E., Lee, K., Southworth, C., \& Tucker, S. (2010). The new age of stalking: Technological implications for stalking. Juvenile and Family Court Journal, 61(4), 3955.

Furedi, F. (2007). The only thing we have to fear is the 'culture of fear' itself. American Journal of Sociology, 32, 231-234.

Gotell, L. (2002). The ideal victim, the hysterical complainant, and the disclosure of confidential records: The implications of the charter for sexual assault law. Osgoode Hall Law Journal, 40, 251.

Gray, E. (Jan 27 2014). This true love tester bra is one step away from a chastity belt. Retrieved from https://www.huffingtonpost.ca/entry/true-love-bra-tester_n_4673656. 
Innovating the problem away? A critical study of anti-rape technologies

Hall, R. (2004). It can happen to you: Rape prevention in the age of risk management. Hypatia, 19(3), 1-18.

Halligan, S., Michael, T., Clark, D., \& Ehlers, A. (2003). Posttraumatic stress disorder following assault: The role of cognitive processing, trauma memory, and appraisals. Journal of Consulting and Clinical Psychology, 71(3), 419-431.

Henry, N., \& Powell, A. (2016). Sexual violence in the digital age: The scope and limits of criminal law. Social \& Legal Studies, 25(4), 397-418.

Hine, C. (2000). Virtual ethnography. Thousand Oaks, CA: Sage Publications Ltd.

Hlavka, H. (2014). Normalizing sexual violence: Young women account for harassment and abuse. Gender \& Society, 28(3), 337-358.

Hollander, J. (2014). Does self-defense training prevent sexual violence against women? Violence Against Women, 20(3), 252-269.

Hollander, J. (2018). Women's self- defense and sexual assault resistance: The state of the field. Sociology Compass, e12597.

Horvath, M and Brown, J., (2007). Alcohol as drug of choice: Is drug-assisted rape a misnomer?. Psychology, Crime and Law, 13(5), 417-429.

Htun, M., \& Weldon, S. (2012). The civic origins of progressive policy change: Combating violence against women in global perspective, 1975-2005. American Political Science Review, 106(3), 548-569. 
Innovating the problem away? A critical study of anti-rape technologies

Jackson-Edwards, P. (August 5, 2015). 'I want to help jail an attacker': Student invents GPS rape alarm that tells police the victim's exact location. Retrieved from http://www.dailymail.co.uk/femail/article-3185071/Student-invents-rape-alarm-tellspolice-victim-s-exact-location-neighbour-s-terrifying-assault-blockflats.html\#ixzz5Gq88Ha6B.

Kilpatrick, D., Resnick, H., Ruggiero, K., Conoscenti, L., \& McCauley, J. (2007). Drugfacilitated, incapacitated, and forcible rape: A national study. United States: National Criminal Justice Reference Service.

Leonetti, C. (2017). Abracadabra, hocus pocus, same song, different chorus: The newest iteration of the science of lie detection. Richmond J of Law \& Technology, 24(1), 1-35.

Lemieux, A. M., \& Felson, M. (2012). Risk of violent crime victimization during major daily activities. Violence and victims, 27(5), 635-655.

Leslie, K. (Feb. 4, 2018). 2 Cal Poly grads look to stop sexual assaults with this new crowdalert app. Retrieved from http://www.sanluisobispo.com/news/business/technology/article198363729.html.

Lievore, D. (2005). Prosecutorial decisions in adult sexual assault cases. Canberra, Australia: Australian Institute of Criminology.

Maher, E. (Oct. 20 1015). This necklace could save your life. Retrieved from https://www.theodysseyonline.com/interview-roar-for-good-co-founder-anthony-gold

Mason, C., \& Magnet, S. (2012). Surveillance studies and violence against women. Surveillance \& Society, 10(2), 105. 
Innovating the problem away? A critical study of anti-rape technologies

McMillan, L. (2018). Police officers' perceptions of false allegations of rape. Journal of Gender Studies, 27(1), 9-21.

McMillan, L. (2013). Sexual victimisation: Disclosure, Responses and Impact, in Lombard, N. \& McMillan, L. eds. Violence Against Women: Current Theory and Practice for Working with Domestic Abuse, Sexual Violence and Exploitation, Research Highlights in Social Work Series, Jessica Kingsley.

McMillan, L. \& Thomas, M. (2009). Police Interviews of Rape Victims: Tensions and Contradictions in Rape: Challenging Contemporary Thinking. Horvath, M . \& Brown, J. (eds.). Cullompton: Willan Publishing.

McMillan, L. (2007). Feminists organising against gendered violence. London: Palgrave Macmillan.

McMillan, L., \& White, D. (2015). 'Silly girls' and 'nice young lads': Vilification and vindication in the perceptions of medico-legal practitioners in rape cases. Feminist Criminology, 10(3), 279-298.

Messner, M. (2016). Bad men, good men, bystanders: Who is the rapist?. Gender \& Society, 30(1), 57-66.

Möller, A., Söndergaard, H., \& Helström, L. (2017). Tonic immobility during sexual assault-a common reaction predicting post- traumatic stress disorder and severe depression. Acta Obstetricia et Gynecologica Scandinavica, 96(8), 932-938.

Mulla, S. (2008). Gender-based violence in the U.S. Retrieved from http://www.americananthropologist.org/2018/04/03/gender-based-violence-in-the-us/. 
Innovating the problem away? A critical study of anti-rape technologies

Murano, G. (September 7, 2013). 10 anti-rape devices. Retrieved from https://www.oddee.com/item_98705.aspx.

O’Malley, P. (1996). Risk and responsibility. In A. Barry, T. Osborne, \& N. Rose (Eds.) Foucault and political reason: Liberalism, neo-liberalism and rationalities of government (pp. 189-207). Chicago: University of Chicago Press.

Palisetty, R. (February 3, 2018). Change-makers. Retrieved from http://www.dailypioneer.com/vivacity/change-makers.html.

Parnis, D., \& Du Mont, J. (2006). Symbolic power and the institutional response to rape: Uncovering the cultural dynamics of a forensic technology. Canadian Review of Sociology/Revue canadienne de sociologie, 43(1), 73-93.

Potter, S., \& Stapleton, J. (2011). Bringing in the target audience in bystander social marketing materials for communities: Suggestions for practitioners. Violence Against Women, 17(6), 797-812.

Powell, A., \& Henry, N. (2014). Framing Sexual Violence Prevention. In Henry, N. \& Powell, A., (Eds.) Preventing Sexual Violence. Interdisciplinary Approaches to Overcoming a Rape Culture. (pp. 1-21). London: Palgrave Macmillan.

Rees, G. (2010). 'It is not for me to say whether consent was given or not': Forensic medical examiners' construction of 'neutral reports' in rape cases. Social \& Legal Studies, 19(3), 371-386. 
Innovating the problem away? A critical study of anti-rape technologies

Rees, G., \& White, D. (2012). Vindictive but vulnerable: Paradoxical representations of women as demonstrated in internet discourse surrounding an anti-rape technology. Women's Studies International Forum, (35)6, 426-431.

Robertson, A. (May 20, 2014). Companies are using fear to market lifestyle accessories to women. Retrieved from https://www.theverge.com/2014/5/30/5764794/stop-makingcute-anti-rape-technology.

Sciarretto, A. (January 1, 2015). Stiletto security charms could prevent assault by providing a discreet way to call 911 if you're in trouble. Retrieved from https://www.bustle.com/articles/56441-stiletto-security-charms-could-prevent-assaultby-providing-a-discreet-way-to-call-911-if-youre.

Senn, C., Eliasziw, M., Barata, P., Thurston, W, Newby-Clark, I., Radtke, H., \& Hobden, K. (2015). Efficacy of a sexual assault resistance program for university women. New England Journal of Medicine, 372(24), 2326-2335.

Spencer, C., Mallory, A., Toews, M., Stith, S., \& Wood, L. (2017). Why sexual assault survivors do not report to universities: A feminist analysis. Family Relations, 66(1), 166-179.

Southworth, C., \& Tucker, S. (2006). Technology, stalking and domestic violence victims. Mississippi Law Journal, 76, 667.

Stanko, E. (1997). Safety talk: Conceptualizing women's risk assessment as a 'technology of the soul'. Theoretical Criminology, 1(4), 479-499. 
Innovating the problem away? A critical study of anti-rape technologies

Trumbell, A. (n.d.). Pro(tech)t yourself: A new wearable tech to combat sexual assault. Retrieved from http://www.mscareergirl.com/protecht-new-wearable-tech-combatsexual-assault.

Wajcman, J. (1991). Feminism confronts technology. University Park, PA: The Pennsylvania State University Press.

Walklate, S. (1997). Risk and criminal victimization: A modernist dilemma?. The British Journal of Criminology, 37(1), 35-45.

Womack, T. (April 11 2018). Automating personal safety with wearable smart jewelry. Retrieved from http://www.uab.edu/news/research/item/9329-automating-personalsafety-with-wearable-smart-jewelry.

White, D. \& McMillan, L. (2018). Statutory response to sexual violence: Where doubt is always considered reasonable. In N. Lombard (Ed.) The Routledge Handbook of Gender and Violence (pp. 111-122). London: Routledge.

White, D., \& Rees, G. (2014). Self-defense or undermining the self? Exploring the possibilities and limitations of a novel anti-rape technology. Violence Against Women, 20(3), 360368.

White, D., \& Du Mont, J. (2009). Visualizing sexual assault: An exploration of the use of optical technologies in the medico-legal context. Social Science \& Medicine, 68(1), 1-8. 
Innovating the problem away? A critical study of anti-rape technologies

\section{BIOGRAPHIES}

Deborah White is an Associate Professor in the Department of Sociology at Trent University in Ontario, Canada. Her research focuses on the institutional responses to sexual violence, particularly medico-legal interventions and the role and nature of forensic evidence and experts in criminal justice systems.

Lesley McMillan is Professor of Criminology and Sociology at Glasgow Caledonian University. She is Associate Director of the Scottish Institute for Policing Research and academic lead for public protection research. Her research focusses primarily on sexual violence, with a particular interest in statutory and institutional responses including criminal justice, policing, and medico-legal intervention. 